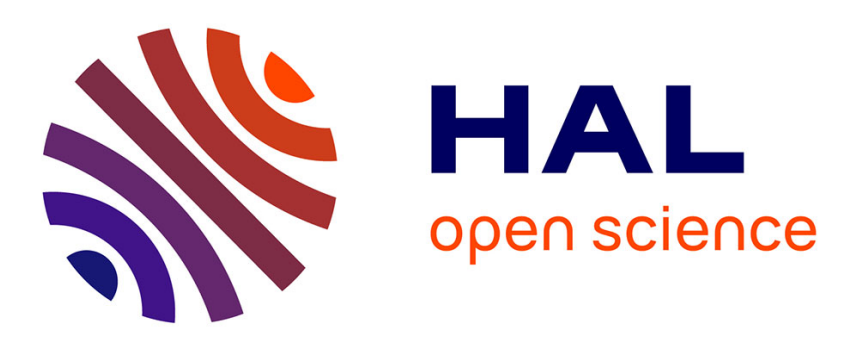

\title{
Influence of chemical architecture of PET on ability to stretch blow moulding
}

Elise Deloye, Jean-Marc Haudin, Noëlle Billon

\section{To cite this version:}

Elise Deloye, Jean-Marc Haudin, Noëlle Billon. Influence of chemical architecture of PET on ability to stretch blow moulding. 11th ESAFORM Conference on Material Forming, Apr 2008, Lyon, France. pp.Pages 715-718, 10.1007/s12289-008-0315-6 . hal-00510331

\section{HAL Id: hal-00510331 \\ https: / hal-mines-paristech.archives-ouvertes.fr/hal-00510331}

Submitted on 18 Aug 2010

HAL is a multi-disciplinary open access archive for the deposit and dissemination of scientific research documents, whether they are published or not. The documents may come from teaching and research institutions in France or abroad, or from public or private research centers.
L'archive ouverte pluridisciplinaire HAL, est destinée au dépôt et à la diffusion de documents scientifiques de niveau recherche, publiés ou non, émanant des établissements d'enseignement et de recherche français ou étrangers, des laboratoires publics ou privés. 


\title{
Influence of chemical architecture of PET on ability to stretch blow moulding
}

\author{
E. Deloye, J-M. Haudin, N. Billon \\ ENSMP - CEMEF, UMR CNRS 7635 - BP 207, 06904 Sophia Antipolis, France \\ URL: www.cemef.cma.fr $\quad$ e-mail: Noelle.billon@ensmp.fr \\ Jean-Marc.haudin@ensmp.fr
}

\begin{abstract}
PET specific properties make this material a good candidate for stretch blow moulding. However chemical architecture of the resin can be varied by the supplier. These changes induce different draw abilities or different behaviours whilst blowing. In this study some well controlled PET resins are characterized both from the point of view of their intrinsic properties and from the point of view of their process abilities. Results enlighten clearly the tight correlation between the chemical structure and the behaviour of the polymer. Coupling effects between the structure, the laboratory properties and the process ability exist making this process a highly not intuitive processing. This study allows, in parallel, proposing a global approach to estimate blowing ability from laboratory analysis.
\end{abstract}

Key words: Stretch blow moulding, PET, structure - processing relationship

\section{INTRODUCTION}

Injection blow moulding is a three-step processing that allows the forming of hollow parts such as bottles. In a first step a preform is injection moulded. This latter is stored and later re heated above glass transition temperature of the material, placed into a mould where forming take place. The forming itself results from 3 stages: firstly, the preform is stretched with a rod (low blow delay), then air is inflated at low pressure $(0.5$ to $0.9 \mathrm{MPa})$ whilst stretching go on and finally stretching is stopped and pressure is increased to 40 bars $(4 \mathrm{MPa})$. The two first stages defined the so-called low blow period.

As far as bottles are concerned and beside specific properties required for the liquid that will fill the bottle, the transformer has to guaranty the transparency, the lightness, the thickness distribution and the mechanical performances of the container.

In the case of PET these constraints imply that the preform must be moulded and blown in the amorphous state. Material must exhibit strain induced crystallisation during blowing keeping high draw ability as thickness reduction can reach value of by 8 to 12 during forming.

Polyethylene terephthalate (PET) is one of the most appropriate materials for this application. Basically, it results from the condensation of terephthalic acid and ethylene glycol to form linear polyester.
However, co monomers can be added to a certain amount to modify the skeleton of the molecule making it less regular, more or less rigid or promoting short branching. Additionally, molar mass can be different from one PET to another.

In consequence, different types of resins are available and one key question is to understand the correlation between this chemical architecture and the behaviour of the material under processing conditions.

General purpose of this study is then to understand this relationships for PET or, at least, to build a general strategy for estimating process ability of PET resins.

\section{EXPERIMENTAL}

To achieve that point well-defined PETs were studied combining laboratory techniques (DSC, DMA, IR spectrometry and tensile tests), laboratory scale processing techniques (free stretch blowing) and industrial scale stretch blow moulding [1].

\subsection{Materials}

Four molecular parameters, which are average molar mass, ratio of flexible, rigid and branched comonomers, are varied as independently as possible. On a whole this results in 11 PET resins of IV ranging from 700 to $1170(10 \mathrm{ml} / \mathrm{g})$. 
All these PETs are semi-crystalline polymers exhibiting the same crystalline phase. Nevertheless, they are very different in terms of crystallisation kinetics (figure 1) from molten state, some of them having significantly faster crystallisation. For a cooling rate of $10{ }^{\circ} \mathrm{C} / \mathrm{min}$ crystallisation temperatures range from $178{ }^{\circ} \mathrm{C}$ to $204^{\circ} \mathrm{C}$.

Differences in crystallisation kinetics result from a complex combination of drastic differences in growth rate of the spherulites (figure 2) and in nucleation efficiency (figure 3). Despite a good characterisation of the resins it is impossible to draw straightforward correlations between molecular parameters and crystallisation phenomenon.

In parallel, glass transition temperatures range from 77 to $81{ }^{\circ} \mathrm{C}$ (using DSC heating rate of $10{ }^{\circ} \mathrm{C} / \mathrm{min}$ ), which is a quite narrow variation.

Consequently, all our polymers remain quenchable even if the minimum cooling rate to be applied to avoid crystallisation depends on the polymer (figure 4) being at least $36{ }^{\circ} \mathrm{C} / \mathrm{min}$ and $150{ }^{\circ} \mathrm{C} / \mathrm{min}$ at a maximum. This upper limit is close to some data of the literature [2] but still lower than others $(300$ ${ }^{\circ} \mathrm{C} / \mathrm{min}$ ) [3], illustrating the wide range of variation of hot crystallisation for PET resins.

However, one must emphasises the fact that neither cold crystallisation of preforms nor strain induced crystallisation of blown parts can be straightforward estimated from these analyses.

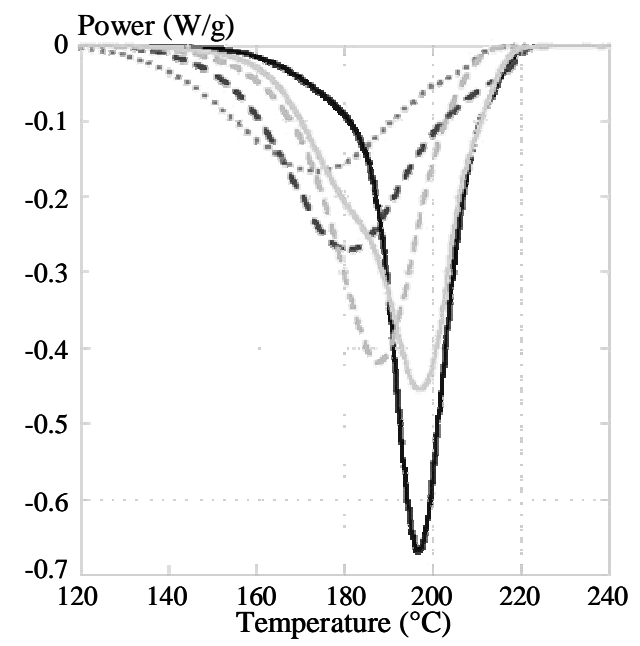

Fig.1.Typical DSC crystallisation traces from molten state at $15^{\circ} \mathrm{C} / \mathrm{min}$ (samples are cryo-powders from perform).

\subsection{Preforms and blowing range}

Indeed, the ability of our materials to be quenched and the persistence of cold crystallisation make them candidates for stretch blow moulding. So, one type of preform (figure 5) is injection moulded according to the state of the art.

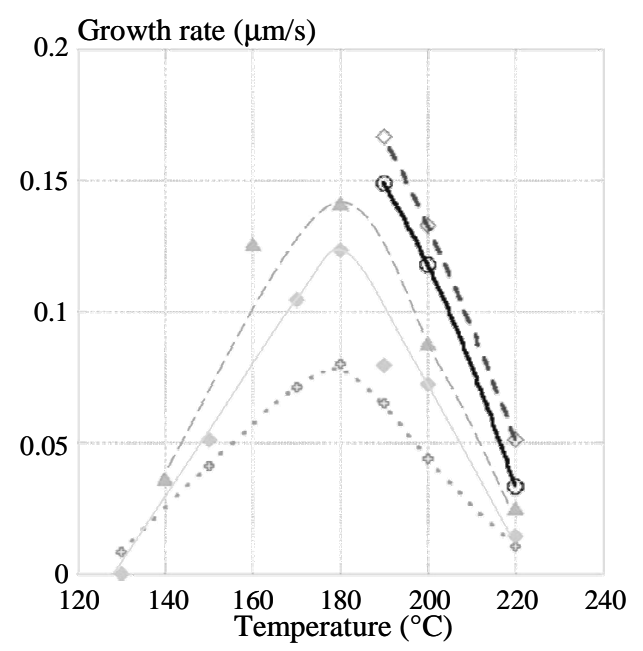

Fig.2. Quiescent and isothermal growth rate for some PETs.
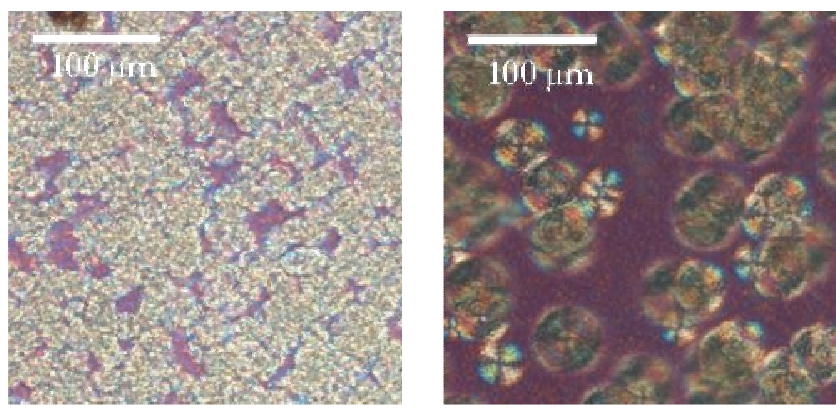

Fig.3. Isothermal crystallisation at $220^{\circ} \mathrm{C}$ : microstructure of the resins having the fastest (on the left, at time $270 \mathrm{~s}$ ) and the slowest (on the right, at time $1200 \mathrm{~s}$ ) crystallisation in figure 1.

Differences in crystallisation kinetics induce significant variations in final transparencies of preforms (figure 5). Consequently, above analysis of hot crystallisation appears of prime interest to predict capability to mould relevant preforms.

To estimate forming range samples are tooled from the preforms and visco-elastic properties are measured using DMTA in flexion.

Processing temperature range is bounded by $\alpha$ transition and cold crystallisation. This range is estimated thanks to DMA (figure $6 \& 7$ ) and can be summarised through curves of crystallisation $\left(\mathrm{T}_{\mathrm{c}}\right)$ and $\alpha$ transition temperatures $\left(\mathrm{T}_{\alpha}\right)$, chosen at the maxima of loss angle (figure 7) vs. frequency (figure 8 ) to account for strain rates effects. This processing range depends on molecular parameters but once again direct correlations are not obvious. On a whole processing range is 85 to $110{ }^{\circ} \mathrm{C}$. Lower limit is controlled by a lost of transparency due to overstretching of the material (figure 9), upper limit is related to crystallisation of the preform. 


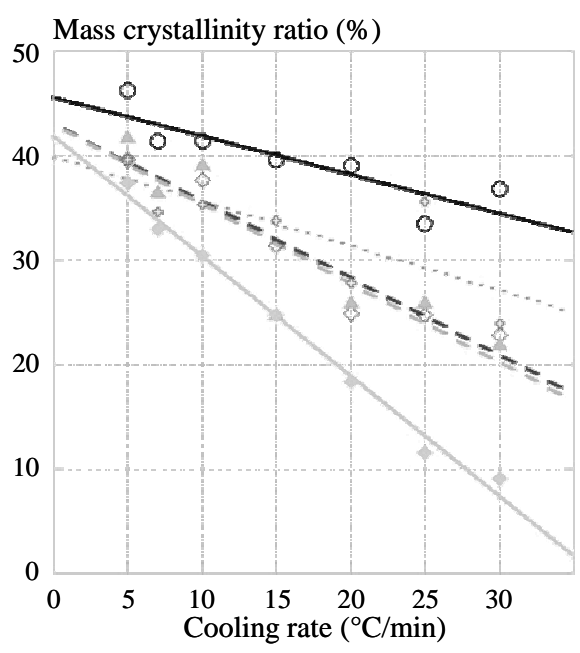

Fig.4. Typical crystallinity ratio in mass vs. cooling rate curves determined by DSC (theoretical enthalpy is chosen to $120 \mathrm{~J} / \mathrm{g}$ ).
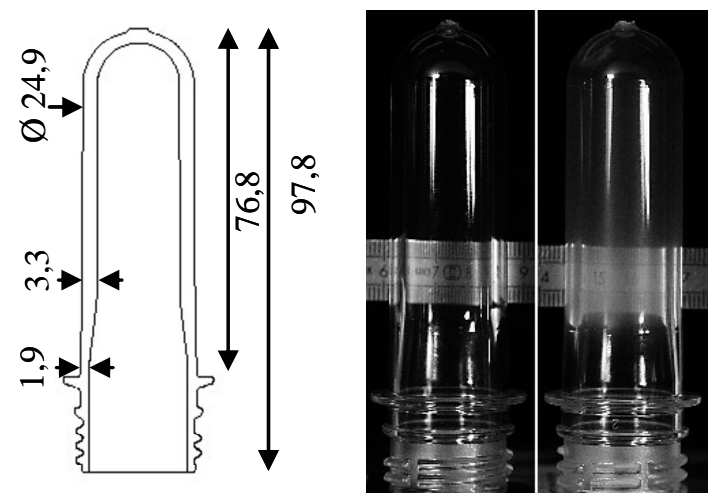

Fig.5. Dimension in $\mathrm{mm}$ and transparencies of the preform; Comparison between the resins having the fastest (left) and the slowest crystallisation kinetics (right).

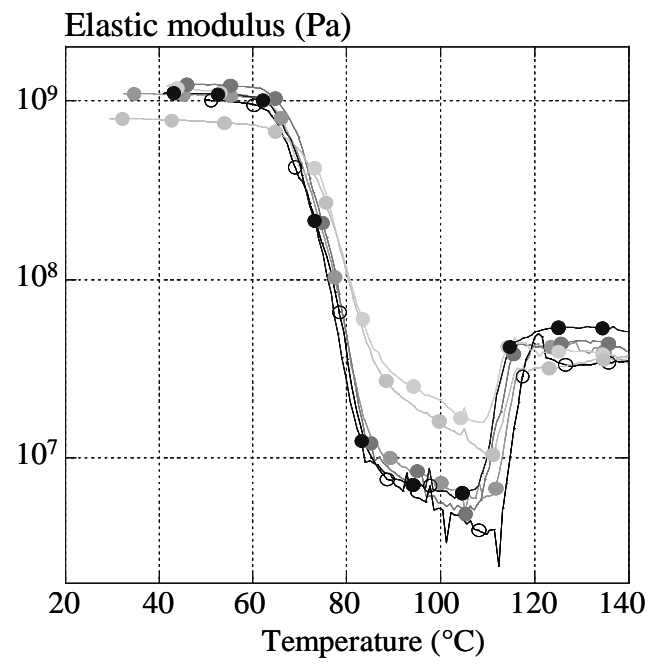

Fig.6. DMA traces at $1 \mathrm{~Hz}$ and $1{ }^{\circ} \mathrm{C} / \mathrm{min}$ : elastic modulus.

\subsection{Blowing ability}

Blowing ability (figure 9) can be explored using the free stretch blow system developed in CEMEF.

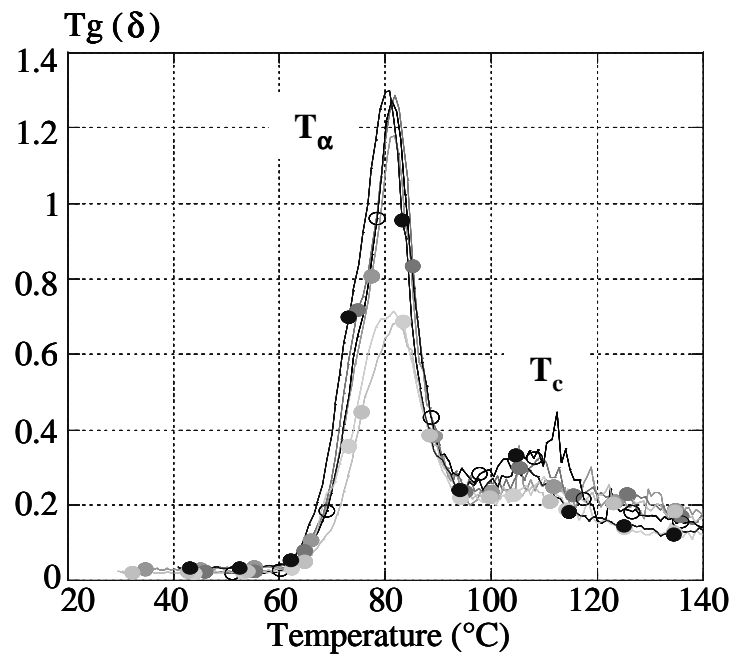

Fig.7. DMA traces at $1 \mathrm{~Hz}$ and $1{ }^{\circ} \mathrm{C} / \mathrm{min}$ : loss angle.

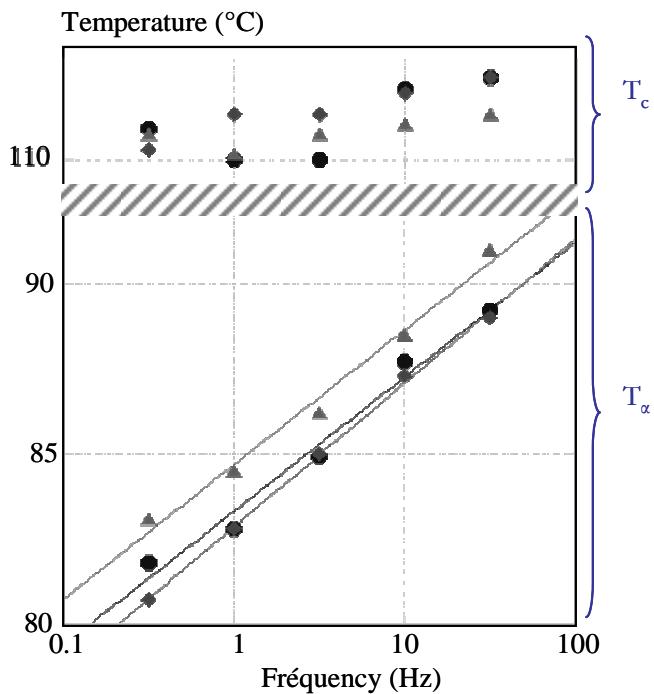

Fig.8. Typical processing ranges for our resins.

\section{Elastic modulus $(\mathrm{Pa})$}

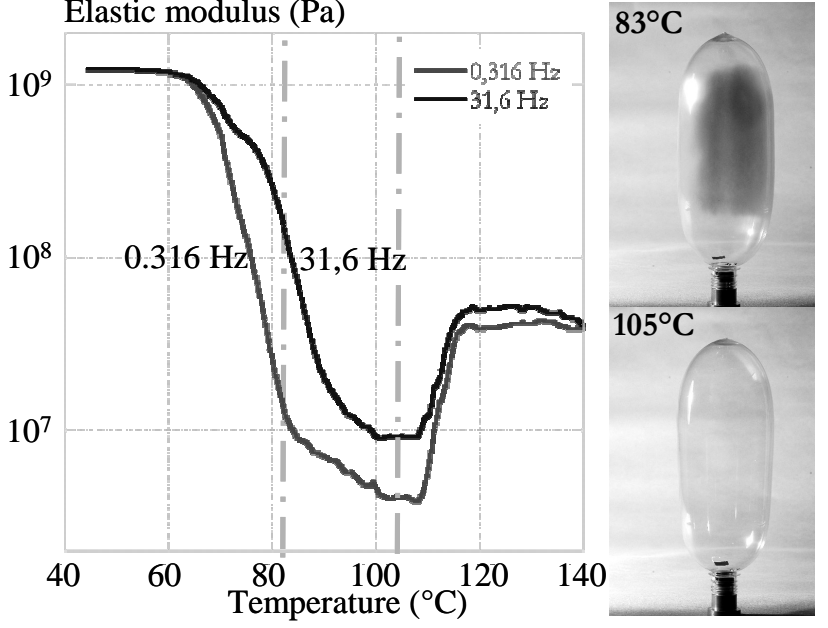

Fig.9. Processing range for $0.7 \mathrm{MPa}$ free blowing.

This lab-scale apparatus allows reproducing IR heating and low blow period $[4,5]$. However prior to such a study it is convenient to characterise IR 
absorption for all the resins [6]. In our case and despite the closeness of the resins, applying the same heating protocol induces differences in temperature as high as $10^{\circ} \mathrm{C}$, which is significant with respect to processing range. So, heating protocol (electric power supplied to the oven) has to be adjusted for each resin to reach a given temperature. As an example, power must be increased by $25 \%$ from the most easily heated resins to the less easily heated PET to get an average temperature of $100{ }^{\circ} \mathrm{C}$ for both resins. Once temperatures are well controlled accurate comparison between resins can be performed (figure 10).

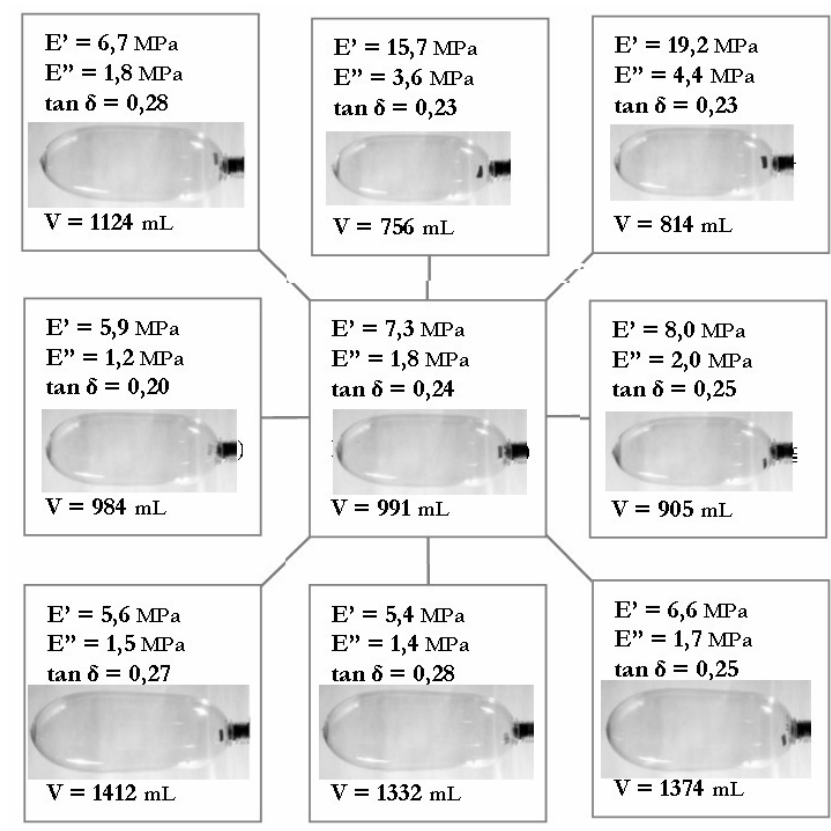

Fig.10. Blown parts for 9 resins at $100{ }^{\circ} \mathrm{C}$ with the same set of parameters (rod velocity $0.8 \mathrm{~m} / \mathrm{s}$, stretch length $130 \mathrm{~mm}$, low blow delay $8,5 \%$ of the stretching length, pressure $0.7 \mathrm{MPa}$ and blowing duration $200 \mathrm{~ms}$ ). E', E" and $\tan \delta$ are the elastic and loss moduli and the tan of loss angle at $1 \mathrm{~Hz}$ and $100{ }^{\circ} \mathrm{C}$, respectively. $\mathrm{V}$ is the volume of the final part.

The use of the same set of controlling parameters does not lead to the same blown part. From all our trials one can conclude that: final volume, shape and diameter, pressure measured in the part during blowing, local bi-axial stretching path and strain rate during forming depend on the resin and the blowing temperature. That is, each resin reaches its own final shape with its own deformation path.

The way the forming is controlled combines more or less all the aspects of the resin behaviour. For example one can see in figure 10 that, on an average, the stiffer the resin the lower the final volume. But, this general trend is not rigorous when looking at details.

Same conclusion can be done for strain rate, which is roughly lower for more rigid PET.

\section{DISCUSSION AND CONCLUSION}

Blowing ability and the estimate of processing zones for PET resins must account for all properties. Beside molten state crystallisation, which controls the quenching ability of the resins, IR absorption, which rules behaviour during heating, one has to account for all the constitutive aspects of the behaviour; initial stiffness, strain hardening, strain rate and temperature sensitivity.

Within the frame of statistical approach (central components analysis), it is possible to sort the blowing conditions for all the resins with respect to the volume, the shape and the transparency of the parts and to suggest one unique 2D form ability surface accounting for six mains parameters: the average temperature of the perform, $\mathrm{T}$, the elastic modulus at $1 \mathrm{~Hz}$ and $\mathrm{T}$, the shift factor at $\mathrm{T}$ as estimated in DMA (that rules strain rate and temperature sensitivity), maximum strain rate and amount of bi axiality during free blowing, uniaxial natural draw ratio and stress at the maximum strain rate. In other words minimum characterisation consists of DMA analysis to build a master curve and estimating shift factors, tensile experiments at control strain rates and one free blow experiments to estimate "natural strain rate". The use of bi-axial tests should simplify this approach.

\section{REFERENCES}

1. E. Deloye, PhD Thesis, Ecole des Mines de Paris, France, 2006.

2. V. Brucato, A. Donarelli, S. Piccarolo and G. Titomanlio,'Analysis of non-isothermal crystallisation kinetics of PET'. Proc. of the European Meeting of the PPS (1995).

3. F.J. Balta Calleja, M.C. Garcia Gutierrez, D.R. Rueda and S. Piccarolo, 'Structure development in poly(ethylene terephthalate) quenched from the melt at high cooling rates : X-ray scattering and microhardness study'. Polymer, 41(2000), 4143-4148.

4. E. Gorlier, PhD Thesis, Ecole des Mines de Paris, France, 2001.

5. E. Gorlier et al., 'Instrumented prototype for stretchblow moulding of PET: a tool for understanding properties - processing relationships', Proc. of the $4^{\text {th }}$ Int. ESAFORM Conf. (2001) 345-348.

6. E. Deloye, J-M. Haudin and N. Billon, 'Influence of the PET chain structure on its stretch blow moulding ability', Proc. of the $8^{\text {th }}$ Int. ESAFORM Conf. (2005) 889-892. 